Biotechnology for Biofuels

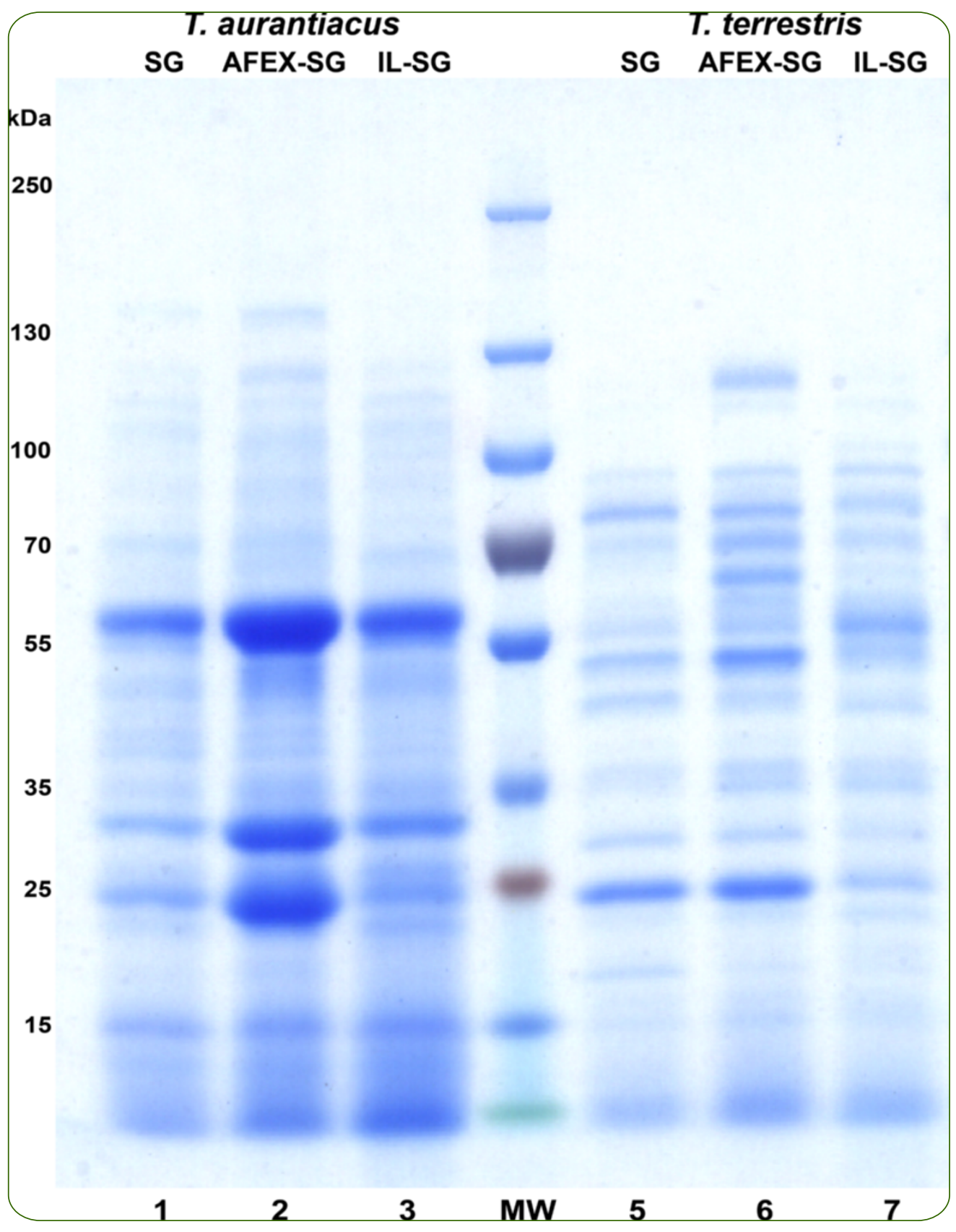

Thermoascus aurantiacus is a promising source of enzymes for biomass deconstruction under thermophilic conditions

McClendon et al. 


\title{
Thermoascus aurantiacus is a promising source of enzymes for biomass deconstruction under thermophilic conditions
}

\author{
Shara D McClendon ${ }^{1,2}$, Tanveer Batth ${ }^{1,2}$, Christopher J Petzold ${ }^{1,2}$, Paul D Adams ${ }^{1,2}$, Blake A Simmons ${ }^{1,3}$
} and Steven W Singer ${ }^{1,4,5^{*}}$

\begin{abstract}
Background: Thermophilic fungi have attracted increased interest for their ability to secrete enzymes that deconstruct biomass at high temperatures. However, development of thermophilic fungi as enzyme producers for biomass deconstruction has not been thoroughly investigated. Comparing the enzymatic activities of thermophilic fungal strains that grow on targeted biomass feedstocks has the potential to identify promising candidates for strain development. Thielavia terrestris and Thermoascus aurantiacus were chosen for characterization based on literature precedents.
\end{abstract}

Results: Thermoascus aurantiacus and Thielavia terrestris were cultivated on various biomass substrates and culture supernatants assayed for glycoside hydrolase activities. Supernatants from both cultures possessed comparable glycoside hydrolase activities when incubated with artificial biomass substrates. In contrast, saccharifications of ionic liquid pretreated switchgrass (Panicum virgatum) revealed that T. aurantiacus enzymes released more glucose than $T$. terrestris enzymes over a range of protein mass loadings and temperatures. Temperature-dependent saccharifications demonstrated that the $T$. aurantiacus proteins retained higher levels of activity compared to a commercial enzyme mixture sold by Novozymes, Cellic CTec2, at elevated temperatures. Enzymes secreted by $T$. aurantiacus released glucose at similar protein loadings to $\mathrm{CTec} 2$ on dilute acid, ammonia fiber expansion, or ionic liquid pretreated switchgrass. Proteomic analysis of the $T$. aurantiacus culture supernatant revealed dominant glycoside hydrolases from families 5, 7, 10, and 61, proteins that are key enzymes in commercial cocktails.

Conclusions: T. aurantiacus produces a complement of secreted proteins capable of higher levels of saccharification of pretreated switchgrass than T. terrestris enzymes. The T. aurantiacus enzymatic cocktail performs at the same level as commercially available enzymatic cocktail for biomass deconstruction, without strain development or genetic modifications. Therefore, T. aurantiacus provides an excellent platform to develop a thermophilic fungal system for enzyme production for the conversion of biomass to biofuels.

Keywords: Thermoascus aurantiacus, Thielavia terrestris, GH 61, Polysaccharide monooxygenases, Fungal secretome, Ammonia fiber expansion, Ionic liquid, 1-ethyl-3-methylimidazolium acetate, Switchgrass (Panicum virgatum)

\footnotetext{
* Correspondence: swsinger@lbl.gov

1 Joint BioEnergy Institute, Emeryville, CA, USA

${ }^{4}$ Earth Sciences Division, Lawrence Berkeley National Laboratory, Berkeley, CA USA

Full list of author information is available at the end of the article
}

\section{() Biomed Central}

(c) 2012 McClendon et al.; licensee BioMed Central Ltd. This is an Open Access article distributed under the terms of the Creative Commons Attribution License (http://creativecommons.org/licenses/by/2.0), which permits unrestricted use distribution, and reproduction in any medium, provided the original work is properly cited. 


\section{Background}

The secretomes of thermophilic fungi have been recently identified as promising sources of enzymes for improving the biochemical conversion of lignocellulosic biomass to biofuels [1]. Readily culturable thermophilic fungi are saprophytic and found in a range of environments, such as compost, where decomposition of organic matter occurs at elevated temperatures [2]. Glycoside hydrolase (GH) enzymes from thermophilic fungi function from $60-80^{\circ} \mathrm{C}$ [1,3-5], whereas commercial fungal cocktails produced by mesophilic fungi perform optimally at $50^{\circ} \mathrm{C}$. Performing saccharifications of pretreated biomass at elevated temperatures contributes to increased conversion rates [6] resulting in shorter incubation times and lower enzyme loadings, as well as reducing the risk of downstream contamination by competing microorganisms for fermentable sugars. Therefore, thermophilic fungi may provide new enzymatic cocktails that are optimized for the industrial biochemical conversion of biomass to sugars for fermentation to biofuels.

Prior to fermentation, lignocellulosic biomass (e.g., corn stover, switchgrass) is typically pretreated chemically to reduce its recalcitrant properties. Pretreatment increases the efficiency of subsequent enzymatic hydrolysis of plant polysaccharides. Certain ionic liquids (ILs) have shown excellent promise in generating cellulose from biomass that readily hydrolyzed by enzymatic cocktails [7]. The majority of ILs that are effective biomass solvents are also toxic to microbes, however fungi have been shown to grow in the presence of high concentrations of some ILs [8]. Recently, a strain of the thermotolerant fungus Aspergillus fumigatus was grown on switchgrass in the presence of $5 \%$ 1-butyl-3-methylimidazolium chloride, abbreviated as $\left[\mathrm{C}_{4} \mathrm{mim}\right] \mathrm{Cl}$, secreting high amounts of cellulase and hemicellulase enzymes. These GHs were shown to retain residual activity in up to $20 \%\left[\mathrm{C}_{4} \mathrm{mim}\right] \mathrm{Cl}$ [9]. In addition, increased IL tolerance has been demonstrated for thermophilic glycoside hydrolases from bacteria $[10,11]$ and archaea [12], suggesting a correlation between thermotolerance and IL tolerance. Therefore, thermophilic fungal enzymes may express enzymes that are tolerant to residual IL present in pretreated biomass, enabling a more costeffective IL conversion process with minimal washing required after pretreatment.

In addition, culture supernatants of thermophilic fungi have been instrumental in identifying new accessory proteins that improve cellulose hydrolysis. Increased glucose release from pretreated barley straw was observed with mixtures of Cellulclast and Novozymes 188 cocktails supplemented with thermophilic fungal crude extracts, indicating that thermophilic fungi produce enhancers for cellulose hydrolysis [13]. Biochemical and proteomic studies identified these enhancement factors as proteins that are members of GH family 61. Addition of purified GH61 proteins from thermophilic fungi Thielavia terrestris or Thermoascus aurantiacus to a commercial Trichoderma reesei enzyme cocktail gave improved cellulose hydrolysis, resulting in 2-fold lower protein loading requirements [14]. Detailed characterization of GH61 from Thermoascus aurantiacus demonstrated that these proteins are $\mathrm{Cu}$ containing monoxygenases that oxidize cellulose chains, facilitating glycoside hydrolase depolymerization [15]. These discoveries demonstrate the potential for studying thermophilic fungi as sources of proteins to improve hydrolysis of lignocellulosic biomass.

Our aim is to gain an understanding of the mechanisms that thermophilic fungi use to deconstruct biomass and develop industrially relevant enzyme cocktails for saccharification of pretreated biomass. Previous studies of thermophilic fungi have indicated that Thielavia terrestris and Thermoascus aurantiacus are promising species for the production of a thermophilic enzymatic cocktail for a lignocellulose deconstruction [13]. In this work, enzymatic hydrolytic activities of supernatants from $T$. aurantiacus and $T$. terrestris grown on untreated and chemically pretreated biomass were compared. This comparison, performed on artificial biomass substrates and pretreated biomass, established T. aurantiacus as a promising system to develop thermophilic enzymatic cocktails.

\section{Results}

\section{Growth of thermophilic fungi on biomass substrates}

Thielavia terrestis NRRL 8126 and Thermoascus aurantiacus ATCC 26904 were cultured on ethanol-extracted switchgrass (SG), ammonia fiber expansion treated switchgrass (AFEX-SG), 1-ethyl-3-methylimidazolium acetate $\left(\left[\mathrm{C}_{2} \mathrm{mim}\right][\mathrm{OAc}]\right)$ treated switchgrass (IL-SG), and microcrystalline cellulose (MCC, Sigma \#435244) for 3 days at $50^{\circ} \mathrm{C}$. Culture supernatants were separated from fungal mycelia and remaining solids by filtration. The protein concentrations of the supernatants were estimated using both Bradford and BCA methods (Table 1). Since the BCA

$\begin{aligned} & \text { Table } 1 \text { Estimated protein concentrations of culture } \\
& \text { supernatants using two protein assay methods }{ }^{\mathbf{1}}\end{aligned}$
\begin{tabular}{llll}
\hline Strain & $\begin{array}{l}\text { Carbon } \\
\text { source }\end{array}$ & $\begin{array}{l}\text { Bradford method } \\
(\mathbf{m g} / \mathbf{m L})\end{array}$ & $\begin{array}{l}\text { BCA method } \\
(\mathbf{m g} / \mathbf{m L})\end{array}$ \\
\hline Thermoascus aurantiacus & SG & $1.0 \pm 0.2$ & $1.1 \pm 0.1$ \\
& AFEX SG & $5.7 \pm 0.2$ & $2.1 \pm 0.1$ \\
& IL SG & $2.1 \pm 0.1$ & $2.0 \pm 0.1$ \\
Thielavia terrestris & MCC & $0.9 \pm 0.3$ & - \\
& SG & $0.8 \pm 0.2$ & $1.1 \pm 0.1$ \\
& AFEX SG & $3.1 \pm 0.1$ & $1.3 \pm 0.1$ \\
& IL SG & $1.5 \pm 0.2$ & $1.0 \pm 0.1$ \\
& MCC & $1.4 \pm 0.2$ & -
\end{tabular}

${ }^{1}$ Three replicates were performed and the error bars represent standard deviation from the mean. 
method is sensitive to the reducing sugars present in the supernatant, the proteins were precipitated using acetone to remove components that may interfere with the protein assay [16]. Values using either assay were comparable, except those generated with AFEX-SG; the higher levels of protein observed by SDS-PAGE in the supernatants from the AFEX-SG grown cultures were more consistent with the estimates obtained for the Bradford assay (see below).

\section{Supernatant activities on artificial substrates}

Cellulase (endoglucanase, cellobiohydrolyase, betaglucosidase) and hemicelluase (xylanase, beta-xylosidase, arabinofuranosidase) activities were measured for these supernatants using artificial substrates (Table 2). Comparison of the cellulase profiles indicated that higher levels of endoglucanase was present in the $T$. terrestris supernatant but the $T$. aurantiacus supernatant possesses higher levels of cellobiohydrolase and $\beta$-glucosidase activity. For hemicellulosic substates, xylanase activity was higher for $T$. aurantiacus but lower for $\beta$-xylosidase activity. In general, the highest activities for the artificial biomass substrates were observed on supernatants generated from growth with SG and MCC.

The eight culture supernatants were screened for glucose release on lignocellulosic biomass substrate; these tests were performed to determine the most active samples from each fungal strain. The enzymatic activities were compared to a commercially available enzyme cocktail, Cellic CTec2 (Novozymes), in the saccharification of $\left[\mathbf{C}_{2} \mathbf{m i m}\right][\mathbf{O A c}]-$ treated switchgrass. Time course data on $\left[\mathbf{C}_{2} \mathbf{m i m}\right]$ [OAc]-treated switchgrass demonstrated that T. aurantiacus enzymes performed comparably to $\mathrm{CTec} 2$ at $50^{\circ} \mathrm{C}$, while $T$. terrestris enzymes released between considerably less glucose compared to the $T$. aurantiacus supernatant (Figure 1). For each strain, supernatants prepared from

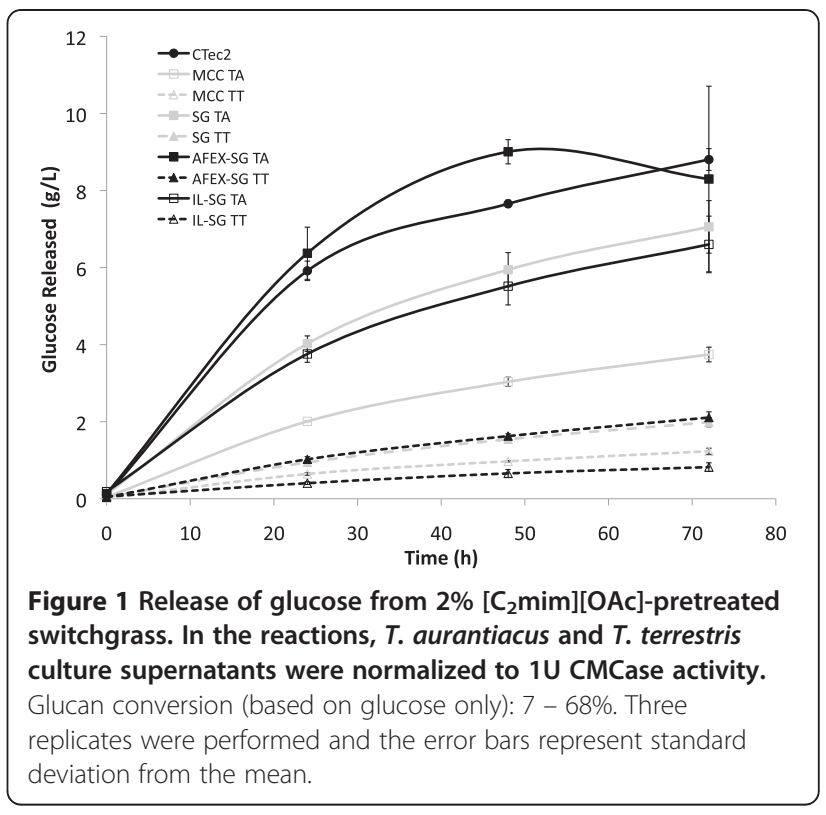

cultures on AFEX-SG were the most active of all the samples in cellulose hydrolysis, followed by supernatants from untreated switchgrass (SG), $\left[\mathrm{C}_{2} \mathrm{mim}\right][\mathrm{OAc}]$-treated switchgrass (IL-SG), and microcrystalline cellulose (MCC), respectively.

\section{Saccharification with culture supernatants from thermophilic fungi}

The saccharification experiment described above established AFEX-grown cultures of $T$. aurantiacus and $T$. terrestris as promising sources of enzymes from thermophilic fungi. $\left[\mathrm{C}_{2} \mathrm{mim}\right][\mathrm{OAc}]$ treated switchgrass (IL-SG) was used as a substrate, which has been shown to be an excellent substrate for commercial enzymatic cocktails [7]. Comparable amounts of glucose were released from IL-SG

Table 2 Secreted cellulase and hemicellulase activities (U/mg or $\mathrm{mU} / \mathrm{mg}$ ) from thermophilic fungi grown on complex biomass substrates ${ }^{1,2,3}$

\begin{tabular}{|c|c|c|c|c|c|}
\hline Strain/Carbon source & CMC (U/mg) & $\mathrm{pNPC}(\mathrm{mU} / \mathrm{mg})$ & pNPG (mU/mg) & Xylan (U/mg) & $\mathrm{pNPX}(\mathrm{mU} / \mathrm{mg})$ \\
\hline \multicolumn{6}{|l|}{ T. aurantiacus } \\
\hline Switchgrass & $0.17 \pm 0.03$ & $34.4 \pm 1.31$ & $177.3 \pm 2.71$ & $0.67 \pm 0.01$ & $8.8 \pm 0.81$ \\
\hline AFEX Switchgrass & $0.04 \pm 0.01$ & $25.7 \pm 0.40$ & $45.6 \pm 1.71$ & $0.10 \pm 0.02$ & $12.4 \pm 1.63$ \\
\hline IL Switchgrass & $0.02 \pm 0.01$ & $9.8 \pm 0.26$ & $54.8 \pm 0.43$ & $0.35 \pm 0.01$ & $10.3 \pm 1.09$ \\
\hline Microcrystalline Cellulose & $1.94 \pm 0.22$ & $12.5 \pm 1.60$ & $93.8 \pm 12.86$ & $1.90 \pm 0.62$ & $6.92 \pm 0.49$ \\
\hline \multicolumn{6}{|l|}{ T. terrestris } \\
\hline Switchgrass & $0.79 \pm 0.02$ & $11.3 \pm 0.62$ & $26.1 \pm 1.14$ & $2.44 \pm 0.38$ & $5.7 \pm 0.47$ \\
\hline AFEX Switchgrass & $0.24 \pm 0.01$ & $3.7 \pm 0.07$ & $5.7 \pm 1.21$ & $0.66 \pm 0.05$ & $0.8 \pm 0.37$ \\
\hline IL Switchgrass & $0.23 \pm 0.02$ & $7.8 \pm 0.25$ & $5.7 \pm 0.23$ & $1.02 \pm 0.05$ & $3.8 \pm 0.41$ \\
\hline Microcrystalline Cellulose & $1.24 \pm 0.23$ & $16.2 \pm 4.38$ & $6.9 \pm 1.76$ & $3.27 \pm 1.12$ & $4.17 \pm 1.27$ \\
\hline
\end{tabular}

${ }^{1}$ Specific activities based on protein concentrations obtained using the Bradford method.

2 Three replicates were performed and the error bars represent standard deviation from the mean.

${ }^{3}$ Activities represented by each substrate is described in the Methods section. 


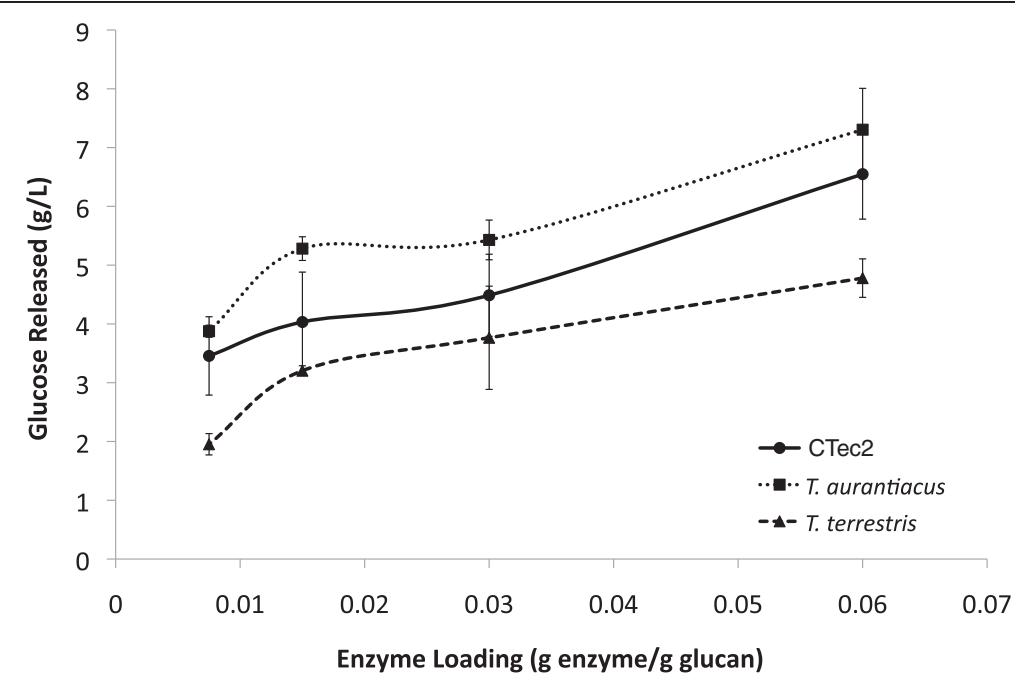

Figure 2 Glucose released from $\left[\mathrm{C}_{2}\right.$ mim] [OAc]-treated switchgrass at different enzyme loadings for culture supernatants from AFEX-SG grown $T$. aurantiacus and $T$. terrestris compared to equivalent enzyme loading from Cellic CTec2. The reactions were performed at $60^{\circ} \mathrm{C}$ with $2 \%(\mathrm{w} / \mathrm{v})\left[\mathrm{C}_{2} \mathrm{mim}\right][\mathrm{OAc}]$-pretreated switchgrass. Three replicates were performed and the error bars represent standard deviation from the mean.

from T. aurantiacus enzymes and CTec2 at a range of protein loadings (Figure 2). Activities from T. terrestris were consistently lower at all protein loading levels. These trends were also observed when saccharifications were performed at different temperatures (Figure 3). The CTec2 cocktail and the AFEX-SG grown $T$. aurantiacus supernatant had the highest relative activity at $50^{\circ} \mathrm{C}$; however the $T$. aurantiacus supernatant released almost 3-fold more glucose from IL-SG at $70^{\circ} \mathrm{C}$ than CTec2 and the T. terrestris supernatant. In contrast, the AFEXSG $T$. terrestris supernatant had an activity maximum at $60^{\circ} \mathrm{C}$, but the T. aurantiacus enzymes were 2-fold more active at the same temperature.

Saccharifications of this supernatant were the tested against dilute acid and AFEX-SG, which are more recalcitrant substrates compared to IL-SG [7,17]. Comparison of saccharification of dilute acid and AFEX-SG switchgrass by the $T$. aurantiacus and $\mathrm{CTec} 2$ indicated that at high enzyme loadings, more glucose was released by the T. aurantiacus supernatant compared to the CTec2 cocktail for all three substrates (Figure 4). High and low enzyme loadings were applied as suggested by CTec2

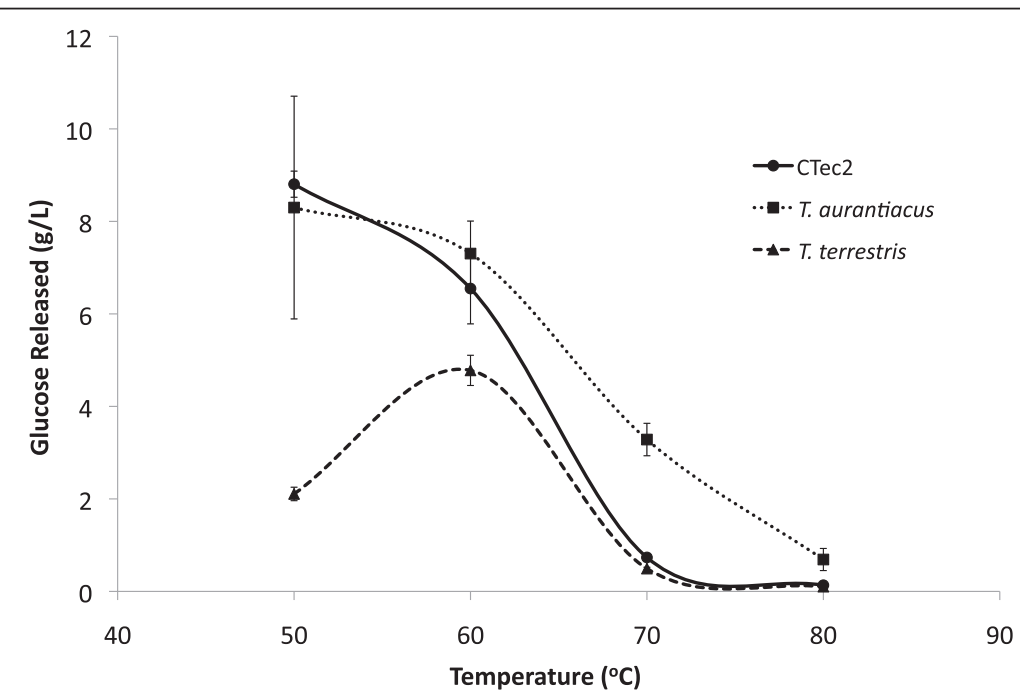

Figure 3 Temperature profile of the saccharification of $\left[\mathrm{C}_{2} \mathrm{mim}\right][\mathrm{OAc}]$-pretreated switchgrass with $T$. aurantiacus/T. terrestris culture supernatants and Cellic CTec2. Enzyme loading was set at $0.06 \mathrm{~g}$ enzyme/g glucan and biomass loading was $2 \%$ [ $\mathrm{C}_{2}$ mim] [OAc]-pretreated switchgrass. Three replicates were performed and the error bars represent standard deviation from the mean. 


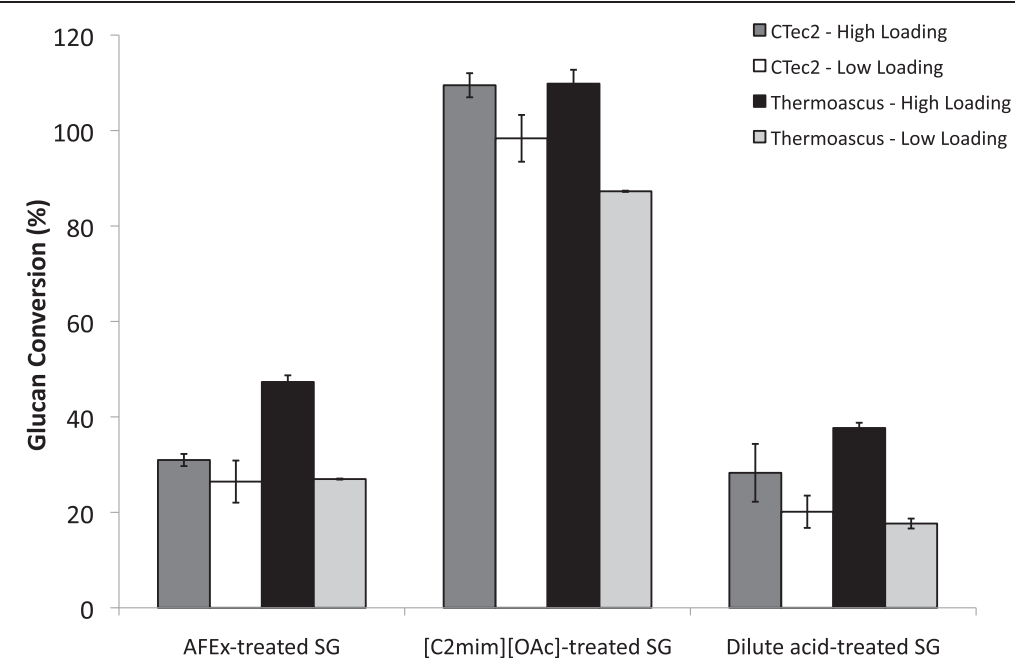

Figure 4 Conversion of glucan to glucose and cellobiose using culture supernatants from AFEX-SG grown T. aurantiacus and Cellic $\mathrm{CTec} 2$ on various pretreated biomass substrates. Reaction conditions were: $(2 \% \mathrm{w} / \mathrm{v})$ biomass, $60^{\circ} \mathrm{C}, \mathrm{pH} 5$ for 72 hours with mixing. Switchgrass substrates were pretreated in three different ways: $\mathrm{LL}$ - ionic liquid, $\left[\mathrm{C}_{2}\right.$ mim] $[\mathrm{OAc}] ; \mathrm{DA}$ - dilute acid, $\mathrm{H}_{2} \mathrm{SO}_{4} ; \mathrm{AFEX}_{-}, \mathrm{NH}_{4}$. The saccharification reactions were performed at two different enzyme loadings, corresponding to recommended high and low enzyme loadings for Cellic Ctec2 (http://www.bioenergy.novozymes.com/). Equal amounts of protein from both T. aurantiacus supernatants and Cellic CTec2 were added to each reaction (g enzyme/g glucan): AFEX-high/low 0.065/0.016; IL-high/low 0.046/0.011; DA-high/low 0.043/0.010. Three replicates were performed and the error bars represent standard deviation from the mean.

recommendations, with $1-6 \%(\mathrm{w} / \mathrm{w})$ enzyme to cellulose representing the range of low to high enzyme concentrations.

\section{Proteomic analysis of the T. aurantiacus secretome}

Proteomic analysis of the T. aurantaicus supernatants was performed to determine abundant proteins that may be responsible for the observed saccharification activity. Analysis of the $T$. aurantiacus supernatants showed distinct protein band patterns for each cultivation condition on untreated and pretreated switchgrass (Figure 5). The AFEX-SG supernatant had three prominent protein bands ( $\sim 50 \mathrm{kDa}, \sim 35 \mathrm{kDa}$, and $\sim 25 \mathrm{kDa}$ ), which were present at lower relative abundances in the other cultivations. Mass spectrometry analysis of the peptides from these three bands revealed that they predominantly consisted of four glycoside hydrolases: GH 7 (cellobiohydrolase), GH 5 (endoglucanase), GH10 (xylanase), and GH61 (copperdependent polysaccharide monooxygenase) (Table 3). Visual comparison to $T$. terrestris demonstrated that there were no comparable prominent bands observed for the three cultivation conditions, which was consistent with the lower activity, therefore the $T$. terrestris bands were not excised for analysis.

\section{Discussion}

In this work, we have shown that culture supernatant recovered from growth of $T$. aurantiacus on AFEX-SG exhibited high levels of saccharification activity on IL-SG. The higher levels of protein in the supernatants from the
AFEX-SG grown supernatants may be due to additional nitrogenous compounds formed during the AFEX process [18]. The $T$. aurantiacus activity was 2-4 fold higher than the culture supernatant from $T$. terrestris at comparable protein amounts. CMCase activity was not predictive of saccharification activity, as supernatants from $T$. aurantiacus showed up to 11.5-fold lower activity on CMC compared to supernatants from $T$. terrestris. Cellobiohydrolase (pNPC) and $\beta$-glucosidase (pNPG) activities correlated with overall saccharification activities, demonstrating that exo-acting cellulases are critical for efficient saccharification of cellulose to glucose [19].

T. aurantiacus supernatant saccharification activities were comparable to the commercial enzymatic mixture Cellic CTec 2 at $50^{\circ} \mathrm{C}$ at similar protein mass loadings and retained higher levels of activity up to $70^{\circ} \mathrm{C}$. The temperature stability of the T. aurantiacus enzyme mixture is consistent with assays performed on purified endoglucanase and cellobiohydrolase enzymes from $T$. aurantiacus strains [4]. Cellic CTec2 has been shown to produce oxidized sugar products gluconic acid and cellobionic acid, suggesting the presence of GH61, a recently discovered $\mathrm{Cu}$-containing cellulose monoxygenase expressed by many fungi, in the enzyme mixtures [20]. GH 61 from $T$. aurantiacus has been shown to reduce enzyme loadings 2-fold with Celluclast/N188 enzymatic cocktails from Novozymes and to be part of a cellulose oxidoreductase enzymatic system with cellobiose dehydrogenase that is synergistic with the well-studied hydrolytic system $[13,15]$. The presence of a prominent band in the corresponding to 


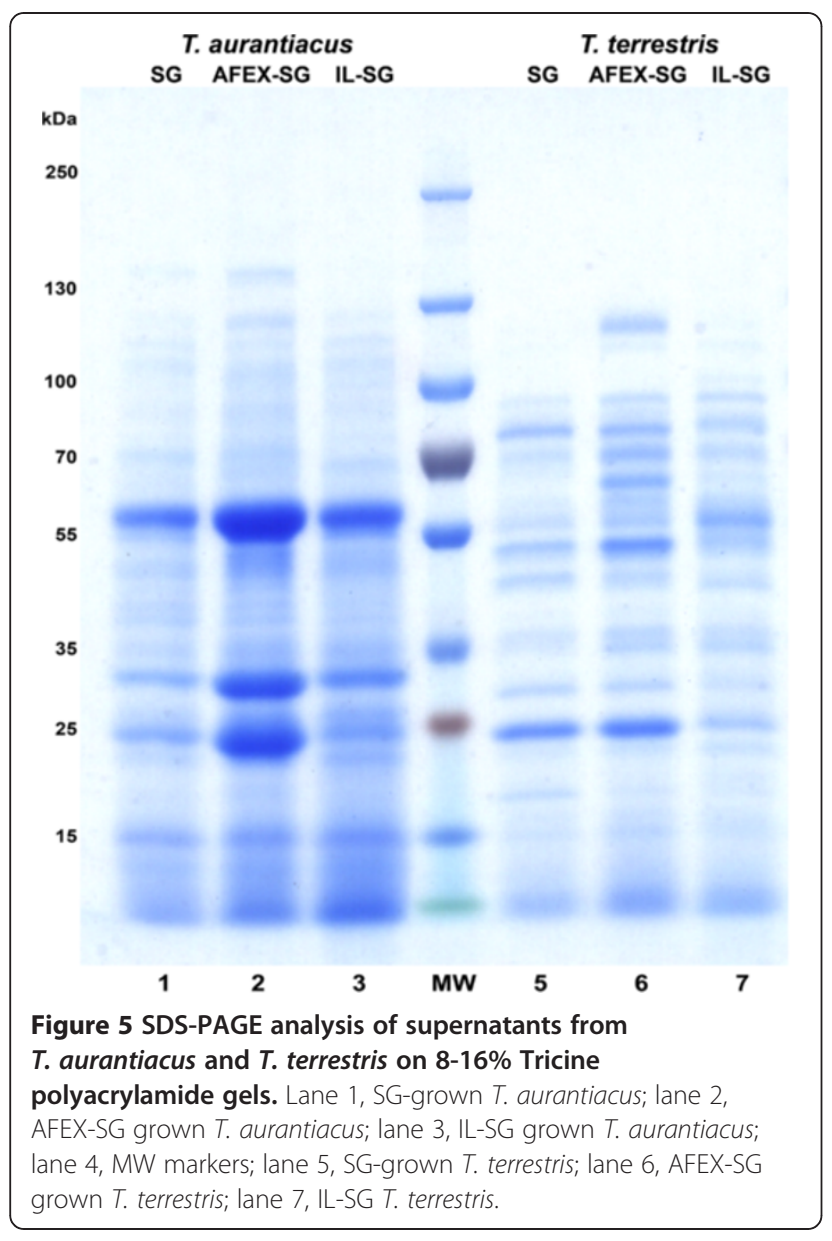

a GH61 protein at $25 \mathrm{kDA}$ in SDS-PAGE analysis of the T. aurantiacus supernatants suggests that it may contribute to the high observed saccharification activity of $T$ aurantiacus supernatants. The observed dominance of GH7, GH5, GH61 and GH10 in the AFEX-SG grown $T$. aurantiacus supernatants is similar to the GH profile of an optimal mixture of enzymes for glucose release from pretreated corn stover that was designed through computational modeling and high-throughput assays, a method referred to as GENPLANT [21]. The similarity between the GENPLANT-designed cocktail and the T. aurantiacus supernatants suggests that T. aurantiacus possesses very favorable properties for efficient cellulose hydrolysis.

Using chemical/UV mutagenesis and plate-based screeing, strains of Trichoderma reesei have been developed that secrete large amounts of cellulases and these strains are the basis for industrial production of cellulases for biomass deconstruction [22]. T. aurantiacus is an attractive candidate for a similar program of mutagenesis and screening, because it already secretes large amounts of cellulase enzymes, as demonstrated in the work described here, and it has a readily observed sexual state that could be used to select for specific mutations to enhance secretion of cellulases and remove deleterious mutations that accumulate during random mutagenesis and screening [23]. Therefore, T. aurantiacus has the potential to be a useful fungal species to understand cellulase secretion and biomass deconstruction under thermophilic conditions.

In conclusion, cultivation of $T$. aurantiacus and $T$. terrestris on biomass substrates revealed that $T$. aurantiacus grown on AFEX-pretreated switchgrass afforded high levels of cellulase enzymes in culture supernatants that were used to saccharify pretreated switchgrass at higher temperature and lower protein loadings than Cellic CTec2. Proteomic analysis of the supernatant demonstrated that the high activity could be attributed to the presence of high levels of proteins from the GH5, GH7, GH10 and GH61 families, which have been shown to be key enzymes in efficient cellulose hydrolysis. This work demonstrates that $T$. aurantiacus is a promising platform for the production of thermophilic enzymes for biomass deconstruction [1].

\section{Methods}

Materials

Fungal strains Thermoascus aurantiacus ATCC 26904 and Thielavia terrestris NRRL 8126 were obtained from American Type Cell Culture Collection. The fungal strains were maintained on potato dextorse agar (PDA) slants at $4^{\circ} \mathrm{C}$. Ethanol-washed and $\left[\mathrm{C}_{2} \mathrm{mim}\right][\mathrm{OAc}]$-treated switchgrass (Panicum virgatum L.) were prepared as previously described [11]. Ammonia fiber expansion (AFEX)-treated and dilute acid-treated switchgrass were obtained as

Table 3 Mass spectrometry analysis of major protein bands isolated from T. aurantiacus AFEX-SG secretome

\begin{tabular}{|c|c|c|c|c|}
\hline Prominent band & Description & Predicted MW & Peptides $(95 \%)^{1}$ & $\%$ Sequence coverage $(95)^{2}$ \\
\hline$\sim 50 \mathrm{kDa}$ & $\begin{array}{c}\text { Possible GH } 7 \text { Cellobiohydrolase [GenBank: } \\
\text { CAD79781] }\end{array}$ & $48 \mathrm{kDa}$ & 250 & 72 \\
\hline$\sim 35 \mathrm{kDa}$ & $\begin{array}{c}\text { GH } 5 \text { Endoglucanase [GenBank: } \\
\text { CAZ67882]/GH10 Xylanase [GenBank: } \\
\text { CAB65468] }\end{array}$ & $37 \mathrm{kDa} / 36 \mathrm{kDa}$ & 249/176 & $72 / 65$ \\
\hline$\sim 25 \mathrm{kDa}$ & GH 61 [PDB: 3ZUD_A] & $24 \mathrm{kDa}$ & 60 & 93 \\
\hline
\end{tabular}

\footnotetext{
${ }^{1}$ Number of unique peptides matching protein with $95 \%$ confidence.

2 Sequence coverage of identified protein with unique proteins matching with $95 \%$ confidence.
} 
generous gifts and prepared using previously reported techniques [24,25]. Composition (cellulose:xylan:lignin content as percentage) of each biomass substrate is as follows: untreated switchgrass (35.1:20:21.2), IL-SG (51:21.4:18.5), AFEX-SG (36:20.8:20), and dilute acidtreated switchgrass (54:7.8:31.5). All chemicals, media, and other substrates were purchased from Sigma-Aldrich (St. Louis, MO) unless otherwise noted.

\section{Thermophilic fungal cultivation}

For each fungal strain, spores from a PDA slant were used to inoculate $50 \mathrm{~mL}$ of potato dextrose broth (PDB) and cultured at $50^{\circ} \mathrm{C}, 150 \mathrm{rpm}$. The seed culture was used to inoculate $50 \mathrm{~mL}$ culture flasks with biomass substrate (10 $\mathrm{g} / \mathrm{L})$, corn steep liquor $(\mathbf{5 0} \%$ solids, concentrate of corn solubles) $(10 \mathrm{~g} / \mathrm{L})$, sodium chloride $(2 \mathrm{~g} / \mathrm{L})$, potassium phosphate $(5 \mathrm{~g} / \mathrm{L})$, calcium chloride dihydrate $(0.1 \mathrm{~g} / \mathrm{L})$, magnesium chloride heptahydrate $(0.5 \mathrm{~g} / \mathrm{L})$, zinc (II) sulfate heptahydrate $(0.002 \mathrm{~g} / \mathrm{L})$, manganese (II) chloride tetrahydrate $(0.008 \mathrm{~g} / \mathrm{L})$, iron (II) sulfate heptahydrate $(0.001 \mathrm{~g} / \mathrm{L})$, copper (II) sulfate heptahydrate $(0.006 \mathrm{~g} / \mathrm{L})$, cobalt (II) chloride hexahydrate $(0.0002 \mathrm{~g} / \mathrm{L})$ and adjusted to $\mathrm{pH} 5$ prior to autoclaving. Fungi were cultured at $50^{\circ} \mathrm{C}, 150 \mathrm{rpm}$ for 3 days. After cultivation, cultures were filtered with Miracloth (EMD Millipore, Billerica, MA) to remove mycelia, followed by a $0.45-\mu \mathrm{m}$ filter with a cellulose acetate membrane (Thermo Scientific, Waltham, MA) for spore removal. The clarified supernatant was stored at $4^{\circ} \mathrm{C}$. Crude enzymes were produced in duplicate cultures and used for all subsequent experiments.

\section{Protein and glycoside hydrolase assays}

Protein concentrations were determined using both Bradford assay (Bio-Rad, Hercules, CA) and bicinchoninic (BCA) assay (Pierce ${ }^{\circledR}$ BCA Protein Assay Kit, Thermo Scientific, Rockford, IL) methods using a 96-well plate (200 $\mu \mathrm{L}$ reaction volume) with bovine serum albumin as the standard. For BCA samples and standards, proteins were first precipitated with acetone and resuspended in $50 \mathrm{mM}$ sodium acetate before measuring final concentration to remove interfering sugar residues [26]. All specific activities reported in this work were calculated using Bradford protein values. Endoglucanase and xylanase activities were assessed using the DNS (3,5-dinitrosalicylic acid) method using carboxymethylcellulose and birchwood xylan as substrates, respectively, with either glucose or xylose as the standard [27]. The enzyme reaction volume was $80 \mu \mathrm{L}$ followed by $80 \mu \mathrm{L}$ of DNS solution to measure released reducing sugars. One unit $(\mathrm{U})$ of cellulase or xylanase activity was defined as the amount of crude protein releasing $\mu \mathrm{mol}$ of reducing sugar per min per $\mathrm{mL}$ of supernatant volume. Cellobiohydrolase (pNPC), $\beta$-D-glucosidase (pNPG), and $\beta$-D-xylosidase (pNPX) activities were determined using their respective $p$-nitrophenyl sugar substrates. $90 \mu \mathrm{L}$ of sugar substrate was incubated with $10 \mu \mathrm{L}$ of diluted enzyme, incubated for $30 \mathrm{~min}$ and quenched with $50 \mu \mathrm{L}$ of $2 \%$ cold sodium bicarbonate. The absorbance of released $p$-nitrophenol was measured at $410 \mathrm{~nm}$. Activities using $p$-nitrophenyl substrates were calculated as $\mu \mathrm{mol}$ $p$-nitrophenol released $\mathrm{min}^{-1} \mathrm{mg}^{-1}$ crude protein. Due to possibility of color interference of the crude enzymes, samples were heat killed at $95^{\circ} \mathrm{C}$ overnight and used to remove background.

\section{Biomass saccharification}

Saccharifications were performed in the presence of $2 \%$ $(\mathrm{w} / \mathrm{v})$ of AFEX-SG, IL-SG, or dilute-acid pretreated switchgrass. Each mixture was prepared in $50 \mathrm{mM}$ sodium acetate, $\mathrm{pH} 5.0$ with the designated amount of enzymes (g protein per g glucan in biomass), which were added after the reaction mixture was prewarmed to the reaction temperature to a final volume of $1 \mathrm{~mL}$ in a $1.5 \mathrm{~mL}$ Eppendorf tube. Saccharifications were carried out at specified temperatures in a shaker for 72 hours. In time-course studies on IL-SG ( $5 \mathrm{~mL}$, performed in $\mathbf{1 5} \mathbf{~ m L}$ Falcon tubes), $500 \mu \mathrm{L}$ samples were removed at designated time points. All hydrolysates were collected via centrifugation at $21,000 \mathrm{xg}$ for $5 \mathrm{~min}$ and $0.45-\mu \mathrm{m}$ filtered to remove large biomass particles prior to sugar analysis. After filtration, samples were kept frozen at $-20^{\circ} \mathrm{C}$ and thawed prior to analysis. Glucose and cellobiose concentrations were measured on an Agilent 1200 Series HPLC system equipped with an Aminex HPX-87H column (Bio-Rad) and Refractive Index Detector. Samples were run with an isocratic 4 $\mathrm{mM}$ sulfuric acid mobile phase. Sugar concentrations were determined using standards containing both glucose and cellobiose. Glucan conversion (mass of glucose plus cellobiose) was calculated using estimated glucan contents of pretreated switchgrass.

\section{Proteomic analysis of thermophilic fungal secretomes}

For SDS-PAGE analysis, supernatants were concentrated 50-fold with 10,000 MWCO PES ultrafiltration column (Vivaspin 500, Sartorius, Germany), loaded onto an 8 16\% Tris-glycine Mini gel (Invitrogen, Carlsbad, CA) and run at $130 \mathrm{~V}$ for 90 minutes. Gels were stained with GelCode Blue Safe Protein Stain (Thermo Scientific). After staining and extensive rinsing, target protein bands were excised and digested using trypsin [28].

Samples were analyzed on an ABSciex TripleTOF 5600 (ABSciex, Foster City, CA) coupled to Eskigent nano-lc systems (Applied Biosystems, Foster City, CA). Peptide samples were injected onto a Pepmap100 $\mu$-guard column (Dionex, Sunnyvale, CA) via a Famos Autosampler (Dionex) and washed for 10 minutes with Buffer A (2\% Acetonitrile, $0.1 \%$ Formic Acid) at $15 \mu \mathrm{L} / \mathrm{min}$. Peptides were eluted onto an Acclaim Pepmap100 C18 column (75 $\mu \mathrm{m} \mathrm{x}$ $150 \mathrm{~mm}, 300 \mathrm{~nL} / \mathrm{min}$ flow rate; Dionex) via a gradient 
consisting of initial starting condition of 5\% buffer B (98\% Acetonitrile, 0.1\% Formic Acid), increasing B to $10 \%$ in 2 minutes followed by a 58 minute ramp to $35 \%$ B. Subsequently, B was increased to $90 \%$ over 3 minutes and held for 7 minutes followed by a ramp back down to $5 \%$ B for 15 minutes to re-equilibrate the column to the original condition. Peptides were introduced to the mass spectrometer by using a Nanospray III source (ABSciex) operating in positive-ion mode $(2400 \mathrm{~V})$ and data acquired with Analyst TF 1.5.1. The TripleTOF 5600 was operated in information dependent acquisition (IDA) mode whereby the ten most intense ions within $400 \mathrm{~m} / \mathrm{z}$ to $1250 \mathrm{~m} / \mathrm{z}$ mass range exceeding 150 counts (charge states $2-5$ ) were selected for MS/MS analysis (high sensitivity mode, UNIT resolution with rolling collision energy). MS/MS spectra were scanned from $100 \mathrm{~m} / \mathrm{z}$ to $1600 \mathrm{~m} / \mathrm{z}$ and were collected for a total accumulation time of $200 \mathrm{~ms}$. Former parent ions were excluded for 16 seconds following MS/MS acquisition. The acquired spectra were exported as.mgf files from Peakview version 1.1.1 (ABSciex) and processed with Mascot version 2.3.02 with a peptide tolerance of $\pm 50 \mathrm{ppm}$ and MS/MS tolerance of $\pm 0.1 \mathrm{Da}$; variable modification was Oxidation (M) with up to one missed cleavage for trypsin. As a limited number of protein sequences from Thermoascus aurantiacus are available, searches were performed against sequenced $T$. aurantaicus proteins available in GenBank combined with a full ORF database from Thielavia terrestris obtained through the Genome Portal of the Joint Genome Institute [29], a list of common contaminants (e.g., trypsin, human keratin) and consisted of 10,007 sequences. Mascot DAT files were uploaded into Scaffold version 3.5 and searched via X!Tandem with the same sequences and parameters.

\section{Abbreviations \\ AFEX: Ammonia Fiber Expansion pretreatment; BCA: Bicinchronic Acid; bG: beta-Glucosidase; [C2mim][OAc]: 1-ethyl, 3-methyl imidazolium acetate; CBH: Cellobiohydrolase; CMC: Carboxymethyl Cellulose; IL: Iionic Liquid pretreatment (in this work, 1-ethyl-3-methylimidazolium acetate); MCC: Microcrystalline Cellulose; SG: Switchgrass.}

\section{Competing interests}

The authors declare that they have no competing interests.

\section{Author's contribution}

SDM and SWS designed the experiments. SDM performed all experiments, analyzed data, and wrote the manuscript. TB and CP setup and performed proteomic sample analysis. SWS, BAS and PAD reviewed and edited the manuscript. All authors read and approved the final manuscript.

\footnotetext{
Acknowledgements

Novozymes (Davis, CA) is acknowledged for the generous gift of enzyme cocktails (Cellic CTec2). Bruce Dale (Michigan State University; Great Lakes Bioenergy (enter) is acknowledged for providing AFEX-treated switchgrass and Mike Himmel (National Renewable Energy Laboratory; BioEnergy Science Center) is acknowledged for providing dilute acid-treated switchgrass. We thank Dr. Ken Vogel at the United States Department of Agriculture, Lincoln, NE, for supplying switchgrass. This work was performed as part of the DOE Joint BioEnergy Institute (http://www.jbei.org) supported by the U.S. Department of Energy, Office of Science, Office of Biological and
}

Environmental Research, through contract DE-AC02-05CH11231 between Lawrence Berkeley National Laboratory and the U.S. Department of Energy.

\section{Author details}

${ }^{1}$ Joint BioEnergy Institute, Emeryville, CA, USA. ${ }^{2}$ Physical Biosciences Division Lawrence Berkeley National Laboratory, Berkeley, CA, USA. ${ }^{3}$ Biomass Science and Conversion Technology Department, Sandia National Laboratories, Livermore, CA, USA. ${ }^{4}$ Earth Sciences Division, Lawrence Berkeley National Laboratory, Berkeley, CA, USA. ${ }^{5}$ Deconstruction Division, Joint BioEnergy Institute, 5885 Hollis Street, Emeryville, CA 94608, USA.

Received: 6 June 2012 Accepted: 13 July 2012

Published: 28 July 2012

\section{References}

1. Berka RM, Grigoriev IV, Otillar R, Salamov A, Grimwood J, Reid I, Ishmael N, John T, Darmond C, Moisan M-C, et al: Comparative genomic analysis of the thermophilic biomass-degrading fungi Myceliophthora thermophila and Thielavia terrestris. Nat Biotech 2011, 29(10):922-927.

2. Maheshwari R, Bharadwaj G, Bhat MK: Thermophilic Fungi: Their Physiology and Enzymes. Microbiol Mol Biol Rev 2000, 64(3):461-488.

3. Brienzo M, Arantes V, Milagres AMF: Enzymology of the thermophilic ascomycetous fungus Thermoascus aurantiacus. Fungal Biology Reviews 2008, 22(3-4):120-130.

4. Bhat MK, Parry NJ, Kalogiannis S, Beever DE, Owen E: Thermostable Cellulase and Xylanase from Thermoascus aurantiacus and Their Potential Industrial Applications. In Glycosyl Hydrolases for Biomass Conversion vol. 769. Washington D C: American Chemical Society; 2000:204-221.

5. Waters DM, Murray PG, Ryan LA, Arendt EK, Tuohy MG: Talaromyces emersonii Thermostable Enzyme Systems and Their Applications in Wheat Baking Systems. Journal of Agricultural and Food Chemistry 2010, 58(12):7415-7422.

6. Viikari L, Alapuranen M, Puranen T, Vehmaanperä J, Siika-aho M: Biofuels: Advances in Biochemical Engineering/Biotechnology. In Thermostable Enzymes in Lignocellulose Hydrolysis Biofuels. vol. 108th edition. Edited by Olsson L. Berlin/Heidelberg: Springer; 2007:121-145.

7. Li C, Knierim B, Manisseri C, Arora R, Scheller HV, Auer M, Vogel KP, Simmons BA, Singh S: Comparison of dilute acid and ionic liquid pretreatment of switchgrass: Biomass recalcitrance, delignification and enzymatic saccharification. Bioresource Technology 2010, 101(13):4900-4906.

8. Petkovic M, Ferguson J, Bohn A, Trindade J, Martins I, Carvalho MB, Leitao MC, Rodrigues C, Garcia H, Ferreira R, et al: Exploring fungal activity in the presence of ionic liquids. Green Chemistry 2009, 11(6):889-894.

9. Singer SW, Reddy AP, Gladden JM, Guo H, Hazen TC, Simmons BA, VanderGheynst JS: Enrichment, isolation and characterization of fungi tolerant to 1-ethyl-3-methylimidazolium acetate. Journal of Applied Microbiology 2011, 110(4):1023-1031.

10. Liang C, Xue Y, Fioroni M, Rodríguez-Ropero F, Zhou C, Schwaneberg U, Ma $Y$ : Cloning and characterization of a thermostable and halo-tolerant endoglucanase from Thermoanaerobacter tengcongensis MB4. Applied Microbiology and Biotechnology 2011, 89(2):315-326.

11. Gladden JM, Allgaier M, Miller CS, Hazen TC, VanderGheynst JS, Hugenholtz P, Simmons BA, Singer SW: Glycoside Hydrolase Activities of Thermophilic Bacterial Consortia Adapted to Switchgrass. Applied and Environmental Microbiology 2011, 77(16):5804-5812.

12. Graham JE, Clark ME, Nadler DC, Huffer S, Chokhawala HA, Rowland SE, Blanch HW, Clark DS, Robb FT: Identification and characterization of a multidomain hyperthermophilic cellulase from an archaeal enrichment. Nat Commun 2011, 2:375

13. Rosgaard L, Pedersen S, Cherry JR, Harris P, Meyer AS: Efficiency of New Fungal Cellulase Systems in Boosting Enzymatic Degradation of Barley Straw Lignocellulose. Biotechnology Progress 2006, 22(2):493-498.

14. Harris PV, Welner D, McFarland KC, Re E, Navarro Poulsen JC, Brown K, Salbo $\mathrm{R}$, Ding $\mathrm{H}$, Vlasenko $E$, Merino $\mathrm{S}$, et al: Stimulation of Lignocellulosic Biomass Hydrolysis by Proteins of Glycoside Hydrolase Family 61: Structure and Function of a Large, Enigmatic Family. Biochemistry 2010, 49(15):3305-3316. 
15. Quinlan RJ, Sweeney MD, Lo Leggio L, Otten H, Poulsen, JC, Johansen KS, Jorgensen Cl, Tovborg M, Anthonsen A, Tryfona T, Walter CP, Dupree P, Xu F, Davies GJ, Walton PH: Insights into the oxidative degradation of cellulose by a copper metalloenzyme that exploits biomass components. Proceedings of the National Academy of Sciences of the United States 2011, 108(37):15079-84.

16. Walker JM: The Bicinchoninic Acid (BCA) Assay for Protein Quantitation. In The Protein Protocols Handbook. Edited by Walker JM. New Jersey: Humana Press; 2002:11-14.

17. Li C, Cheng G, Balan V, Kent MS, Ong M, Chundawat SPS, Sousa L, Melnichenko YB, Dale BE, Simmons BA, et al: Influence of physico-chemical changes on enzymatic digestibility of ionic liquid and AFEX pretreated corn stover. Bioresource Technology 2011, 102(13):6928-6936.

18. Chundawat SPS, Vismeh R, Sharma LN, Humpula JF, Sousa LD, Chambliss CK, Jones AD, Balan V, Dale BE: Multifaceted characterization of cell wall decomposition products formed during ammonia fiber expansion (AFEX) and dilute acid based pretreatments. Bioresource Technology 2010, 101(21):8429-8438.

19. Gao D, Chundawat SP, Krishnan C, Balan V, Dale BE: Mixture optimization of six core glycosyl hydrolases for maximizing saccharification of ammonia fiber expansion (AFEX) pretreated corn stover. Bioresource Technology 2010, 101(8):2770-2781.

20. Cannella D, Hsieh CW, Felby $C$, Jorgensen $\mathrm{H}$ : Production and effect of aldonic acids during enzymatic hydrolysis of lignocellulose at high dry matter content. Biotechnology for Biofuels 2012, 5(1):26.

21. Banerjee G, Car S, Scott-Craig JS, Borrusch MS, Bongers M, Walton JD: Synthetic multi-component enzyme mixtures for deconstruction of lignocellulosic biomass. Bioresource Technology 2010, 101(23):9097-9105.

22. Le Crom S, Schackwitz W, Pennacchio L, Magnuson JK, Culley DE, Collett JR, Martin J, Druzhinina IS, Mathis H, Monot F, et al: Tracking the roots of cellulase hyperproduction by the fungus Trichoderma reesei using massively parallel DNA sequencing. Proceedings of the National Academy of Sciences of the United States of America 2009, 106(38):16151-16156.

23. Pore RS, Larsh HW: First occurrence of Thermoascus aurantiacus from animal and human sources. Mycologia 1967, 59(5):927.

24. Bals B, Rogers C, Jin M, Balan V, Dale B: Evaluation of ammonia fibre expansion (AFEX) pretreatment for enzymatic hydrolysis of switchgrass harvested in different seasons and locations. Biotechnology for Biofuels 2010, 3(1):1.

25. Torget R, Werdene P, Himmel M, Grohmann K: Dilute acid pretreatment of short rotation woody and herbaceous crops. Applied Biochemistry and Biotechnology 1990, 24-25(1):115-126.

26. Brown RE, Jarvis KL, Hyland KJ: Protein measurement using bicinchoninic acid: elimination of interfering substances. Analytical Biochemistry 1989 180(1):136-139.

27. Xiao Z, Storms R, Tsang A: Microplate-based carboxymethylcellulose assay for endoglucanase activity. Analytical Biochemistry 2005, 342(1):176-178.

28. Shevchenko A, Tomas H, Havlis J, Olsen JV, Mann M: In-gel digestion for mass spectrometric characterization of proteins and proteomes. Nat Protocols 2007, 1(6):2856-2860.

29. Grigoriev IV, Nordberg H, Shabalov I, Aerts A, Cantor M, Goodstein D, Kuo A, Minovitsky S, Nikitin R, Ohm RA, et al: The Genome Portal of the Department of Energy Joint Genome Institute. Nucleic Acids Research 2012, 40(D1):D26-32.

\section{Submit your next manuscript to BioMed Central and take full advantage of:}

- Convenient online submission

- Thorough peer review

- No space constraints or color figure charges

- Immediate publication on acceptance

- Inclusion in PubMed, CAS, Scopus and Google Scholar

- Research which is freely available for redistribution

Submit your manuscript at www.biomedcentral.com/submit 